\title{
Study on the pattern of vegetative growth in young dioecious trees of Idesia polycarpa maxim
}

\author{
Sohel Rana ${ }^{1}\left[\right.$ Zhen Liu $^{1}$
}

Received: 11 February 2020 / Accepted: 15 July 2020 / Published online: 21 July 2020

(c) The Author(s) 2020

\begin{abstract}
Key message The dioecious Idesia polycarpa all that males and females do not invest in the same way in growth and branching in quantity, type of axes and in time (annual growth and sequence of these events over time).

Abstract The annual growth of plants is an important indicator for growth and development, especially for younger trees. The aim of this study was to decide the physiological basis for vegetative growth effects on the trunk and crown development in Idesia polycarpa by assessing the effects on variations in bud growth, leaf, and canopy size. This study focused on the annual vegetative growth of young (3-year old) female and male I. polycarpa Maxim trees and their functions are separate. The phenology provides a challenge in the production of resources (seed, oil) and to investigate the effect of sexual specialization. Here we describe the variations between two sexes in terms of vegetative growth in our field studies. The study began in the sprouting season with observations of the gradual growth of the newly sprouting buds. The length of expansion, diameter growth, and leaf production from the terminal bud (TB), lateral terminal bud (LTB) of the first tier of branches (1Y), second tier of branches (2Y), and third tier of branches (3Y) of the trees were measured. The results showed growth differences between female and male groups in the growing year. The length of shoot expansion, diameter, and leaf production were higher for female trees than for male trees. Male trees grew more long and short branches (SB) than the female trees, with large numbers of short branches on the $1 \mathrm{Y}$ and $2 \mathrm{Y}$ of the male trees. Further investigation needed to analyze factors of annual fluctuation of the shoot expansion of the tree, with more studies investigating complex branching phenomenon, flowering, and fruit production in I. polycarpa Maxim.
\end{abstract}

Keywords Annual growth variation $\cdot$ Vegetative growth $\cdot$ Dioecious trees $\cdot$ Sexual dimorphisms $\cdot$ Cumulative DBH

\section{Introduction}

The tree known as "Chinese Wonder Tree" for its multipurpose use, has economic and ecological value. The Idesia polycarpa (Flacourtiaceae) fruit oil has the great potential of being used as a feedstock for medicine, food, and for bio-diesel production to reduce producing cost (Yang et al. 2009). The fruit has a high oil content, confirmed to be edible, and has the potency to be useful in preparation of biodiesel (Jia et al. 2014). In

Communicated by Vospernik.

Zhen Liu

liuzhen@henau.edu.cn

Sohel Rana

sohel.sam@live.com

1 College of Forestry, Henan Agricultural University, 63\# Nongye Road, Zhengzhou 450002, China addition, the seed oil has obvious health effects on the cardiovascular system and has a good effect on hypertension as well as coronary heart disease (Ren 1995; Jun et al. 2004; Zhang et al. 2009a, b). Several studies have already been conducted on the I. polycarpa flower, fruit, oil, and seed; however, studies on vegetative growth, crown development, branching structure, especially in the young stages of male and female growth have not been conducted. Besides, I. polycarpa Maxim is often as "Tree Oil Depot" (Yang 2001; Wang et al. 2014), and the ideal woody, oil, and garden ornamental trees (Liu et al. 2005; Wang et al. 2011) because it is not only used as ornamental and greening tree species but also has very high oil content in its fruit. Due to the hierarchical structure of the crown of the $I$. polycarpa tree, it is airy and light-transmitting, and the canopy has a large number of twigs and can be grown in high yield without special pruning. Studying the pattern of vegetative growth in I. polycarpa Maxim, which can provide important theoretical value and practical significance to the cultivation 
as well as for regulating the crown structure to promote flower and fruit.

The dioecious plants provide an excellent opportunity on the production of resources (seed, oil) and examining the differences between male and female plants throughout the growing year, vegetative growth and in their effect on the evolution of sexual dimorphism in plants. In addition, molecular genetic studies are now starting to discover fully sex-linked markers and genes in dioecious plants, confirming genetic sex determination; such work should help test the genetic basis of plant sex determination, including testing whether dioecy that evolved from monoecious ancestry or in organisms with complex genetics (such as Urtica dioica; Shannon and Holsinger 2007; Glawe and de Jong 2009) differs from that from hermaphrodite progenitors (Charlesworth 2016). Once expressed, gender is likely to remain constant during the lifetime of a tree (Picard 1982; Wallander 2001). Dioecious woody plants have shown sex-specific patterns of extension vegetative growth. The vegetative growth of the tree within-sex competition has been associated with reductions in growth rates (Zhang et al. 2009a, b). However, other studies have reported faster growth rates in females (Grant and Mitton 1979; Sakai and Burris 1985; Willson 1986; Sakai and Sharik 1988; Davidson and Remphery 1990). It is known that diameter at breast height (DBH) is relatively cheaper and can be more accurately obtained than total tree height and that a close relationship usually exists between DBH and height of individual tree stems (Mayer 1936). Knowledge of the relationship between tree height and diameter is useful in a number of contexts, including stand biomass estimation (Huang et al. 1992), and theoretical considerations of tree growth (King 1990).

The main purpose of this study was to describe the effects of vegetative growth and variation on young trees trunk and crown development, and we describe the annual growth process of newly sprouting shoots, its growth and sexual dimorphisms between male and female plants of dioecious woody tree I. polycarpa. The overall objective of the present study was to characterize certain shoot morphology parameters in different parts of the crown by sampling shoots in each designated location and relate this to crown development patterns in young I. polycarpa. Specifically, we characterized the annual vegetative growth differences between male and female I. polycarpa trees, and determine the growth pattern of the trunk, tier of branches, and short branch's effects for crown development in young females and male plants.

\section{Materials and methods}

\section{Study site}

This study was undertaken at the experimental research station $\left(112^{\circ} 42^{\prime} 114^{\circ} 14^{\prime} \mathrm{E}\right.$, and $\left.34^{\circ} 16^{\prime} 34^{\circ} 58^{\prime} \mathrm{N}\right)$, College of
Forestry, Henan Agricultural University, Zhengzhou, Henan Province, China in 2017. The mean annual temperature of this site is $14.2{ }^{\circ} \mathrm{C}$, the frost-free period 215 days, the mean annual precipitation of $650.1 \mathrm{~mm}$, annual sunshine hours are about $2400 \mathrm{~h}$, and the soil is slightly alkaline sandy loam.

\section{Vegetative growth}

This study was conducted on the 3-year old young I. polycarpa Maxim trees. As this species is dioecious, both males and female trees were included. The period of the experiment was from March to October.

\section{Data sampling and preparation}

The 1-year old female and male seedlings were planted under their natural habitats condition in the college of forestry experimental station of Henan Agricultural University in 2014, the seedlings were planted in the two plantation plots, and planting distance maintained was $1.5 \times 1.5 \mathrm{~m}$. The plantation plots condition is similar and the plot to plot distance was nearby $50 \mathrm{~m}$. The terminal bud (TB) and lateral terminal bud (LTB) leave scars that constitute the terminal bud during the winter.

The population consisted of 120 I. polycarpa plants. The vegetative growth of 15 females and 15 male plants ( 7 and 8 plants from two plots for each group), selected at random from different directions (east, west, north, south, and middle portion) of the plantation plot. Trees annual growth unit emerged branches from the stem are considered as $1 \mathrm{Y}$ (first), 2Y (second), and 3Y (third) tier of branches of the tree. The 1Y encompassed growth of the first year branch section (1BS), second year branch section (2BS), and third year branch section (3BS). Correspondingly, the $2 \mathrm{Y}$ encompassed the 2BS and 3BS, the $3 \mathrm{Y}$ encompassed only the 3BS (Fig. 1).

The observation was begun nearby 20 days before the onset of the sprouting of TB and LTB. The first reading was taken 7 days after TB and LTB sprouting. Experimental data were collected every 7 days until October 5th, 2017. The newly sprouting TB and LTB length, diameter were recorded using tree measurement tape, ruler, and a precision digital calipers with the resolution of $0.01 \mathrm{~mm}$. The leaf census was taken for each, weekly estimates of leaf production, the latter number based on scar morphology. Leaf phenology was recorded by scoring the numbers of young, mature, and senescing leaves on the same plants at the same time. The largest and the smallest of all developed leaves were recorded. The measured variables (length, diameter, the number of leaves) always measured on the same buds.

The preceding year's growth units of the female and male tree trunk, first-year growth unit trunk length $=1$ GUTL (2014), Second year growth unit trunk 
Fig. 1 Illustration of the model tree, and crown attributes for the vegetative growth. Different stages of growth, during the study on young I. polycarpa Maxim trees. Sections indicate the different year's growth unit, the group of branches considered as the tier of branches and the newly sprouted terminal buds observed.TB terminal bud, $L T B$ lateral terminal bud, $1 Y$ first tier bud, $2 Y$ second tier of branches, $3 Y$ third tier of branches, $S B$ short branches, $1 B S$ first year branch section, $2 B S$ second year branch section, $3 B S$ third year branch section, $1 G U T L$ first year growth unit trunk length, $2 G U T L$ second year growth unit trunk length, $3 G U T L$ third year growth unit trunk length,

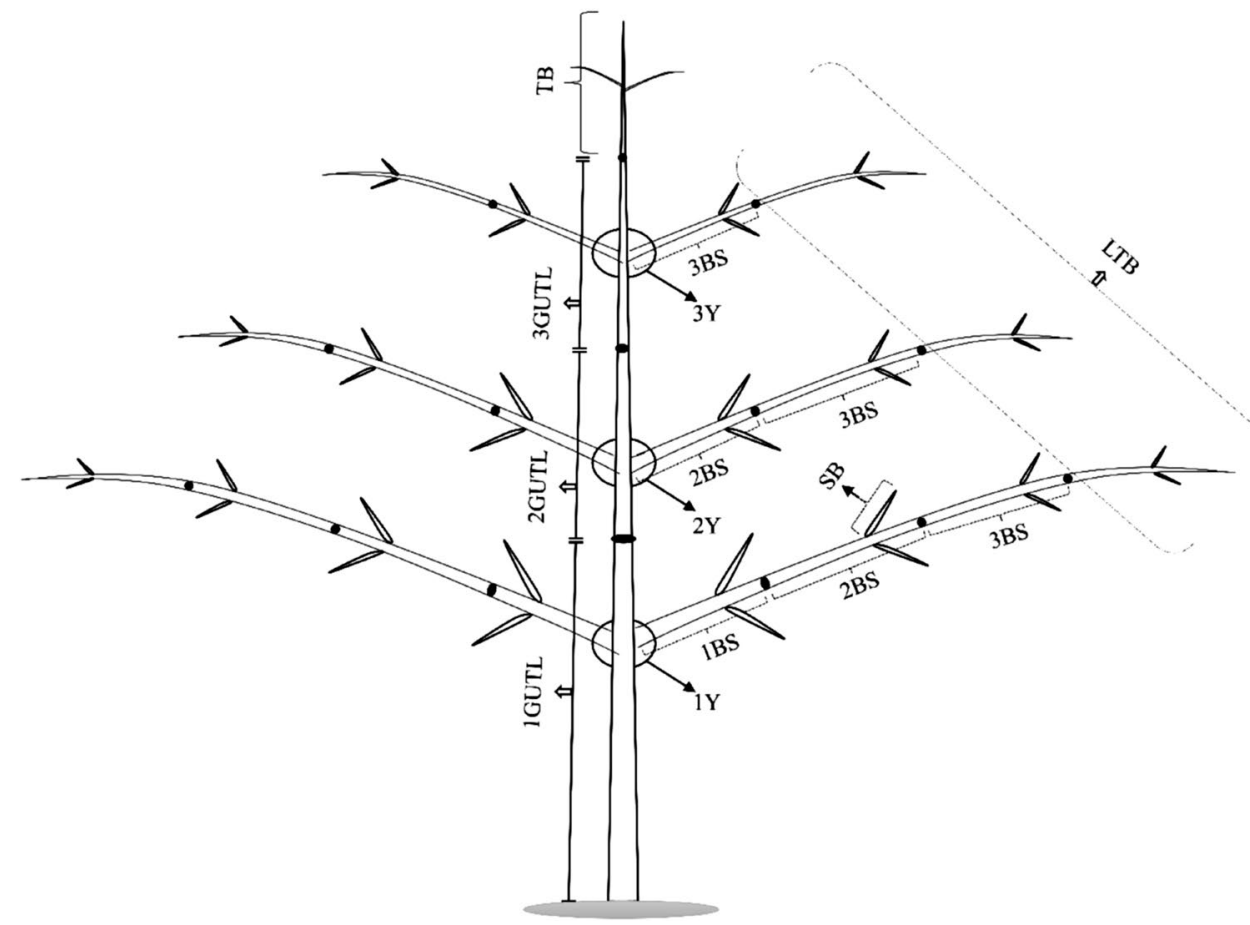

length $=$ 2GUTL (2015), and Third year growth unit trunk length $=3$ GUTL (2016) length and diameter recorded, including the lengths and diameters of the 1Y's of 1BS, $2 \mathrm{BS}$, and $3 \mathrm{BS}$ sections, along the $2 \mathrm{Y}$ 's of $2 \mathrm{BS}$ and $3 \mathrm{BS}$ sections, with the $3 \mathrm{Y}$ 's of $3 \mathrm{BS}$ section. The diameter for each entity (trunk growth unit, TB/LTB, 1BS/2BS/3BS) measured the immediate next part of the adjoining part in between $5 \mathrm{~cm}$.

The number of the long branches arising directly from the main stem during the annual growth (tier of branches) counted and recorded the data individually of female and male groups for comparison. Short branches emerge from the long branches and increased their length and diameter throughout the growing year. The short branches are not emerging immediately on the current growth unit. The short branches numbers were recorded, respectively, the tier of branches and the branch sections followed.

\section{Cumulative growth of DBH}

For the estimation of cumulative DBH growth throughout the year, 22 females and 22 male plants were selected with the same method. The DBH is defined as the tree diameter at breast height (1.3 m above ground). Every 15 days interval the DBH data were taken with precision digital calipers with the resolution of $0.01 \mathrm{~mm}$. Individual data was recorded on separate datasheets for further analysis and comparing between the sexes.

\section{Statistical analysis}

Differences between the sexes was analyzed using the IBM SPSS Statistics 19 program. One-way analysis of variance (ANOVA) and multiple range test using Fisher's least-significant-difference (LSD) procedure at a $95 \%$ confidence level were used to determine the sex differences in length, diameter, and leaf production of the newly sprouted TB, LTB shoots, and trunk length and diameters data were analyzed by the General linear model. Statically significant differences between both sex in 1Y, 2Y, 3Y, and TB were tested using the Duncan multiple range test at $P \leq 0.05$. The variation of DBH between the sexes was analyzed with oneway analysis of variance (ANOVA) and multiple range tests using Fisher's least-significant-difference (LSD). Statically significant differences were tested using the Duncan multiple range test at $P \leq 0.05$.

\section{Results}

\section{Trunk growth patterns}

The growth of the tree trunk during the experimental year was observed. The length of the trunk increased over the experimental year, and the preceding years, along with the diameter. The mean growth of trunk length of female trees was higher than male trees from the 1GUTL, 2GUTL, and 3GUTL but in the 4GUTL (grow in study year) the male 
trees achieved a higher mean trunk length than female trees (current year TB considered as the trunk for the next growing year), when the whole trunk length compared between females and male sexes and significant not exhibited $(P=0.701)$, as result showed (Fig. 2).

Meanwhile, the diameter and length of the annual growth trunk varied with tree age, and the diameter growth

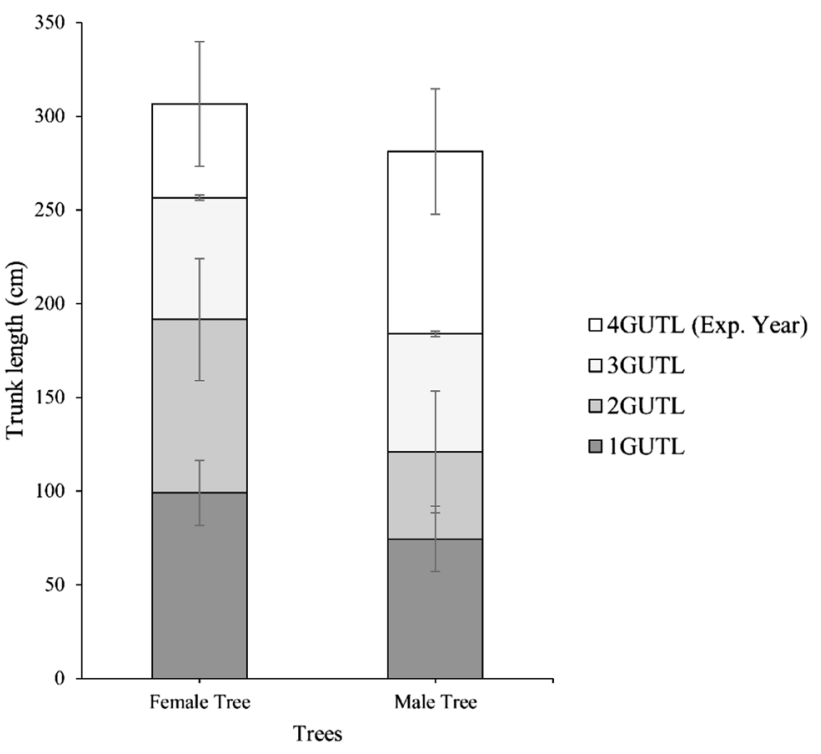

Fig. 2 Trunk length in different years, calculated the mean length for young female and male $I$. polycarpa trees. The different sections indicated different year growth unit. The indication for both 15 female and 15 male trees, respectively. Significant differences not exhibited when the whole stem length (i.e. 1GUTL, 2GUTL, 3GUTL) compared between females and male sexes; $P=0.701$ ). Data values represent the mean $\pm \mathrm{SD}$ of males was higher in the preceding years, also the current year than the female trees. The 1GUTL is greater than the 4GUTL as the annual growth of diameter decreases with tree age. The newly sprouting terminal bud of the tree will subsequently follow at the same trend (Fig. 3).

\section{Crown growth pattern}

\section{Long branches (tier of branches)}

During the growing year TB (current year TB considered as the trunk for the next growing year) length and diameter increased, and the long branches arising directly from the TB during the annual growth, long branches are distributed all around the trunk on successive leaves constituting a tier of branches. In addition, the new tier of branches increased incrementally in length and diameter over the year, but the number of arising branches was not fixed, and they arise randomly. After the growing year, there is no chance to grow a new branch from the same location, and from the trunk unit. The branches that sprouted from the tier of branches of the tree trunk were observed and recorded. It was noted that male trees significantly produced a higher number of branches from the tier of branches of the trunk, whereas female trees produced a less significant number of branches. Across four growing years, the data showed that in the 3 GUTL of $3 \mathrm{Y}$, female and male trees produced on the same number of branches and there is no significant difference were found, whereas in the other year's male trees significantly produced a higher number of long branches than female trees (Fig. 4).

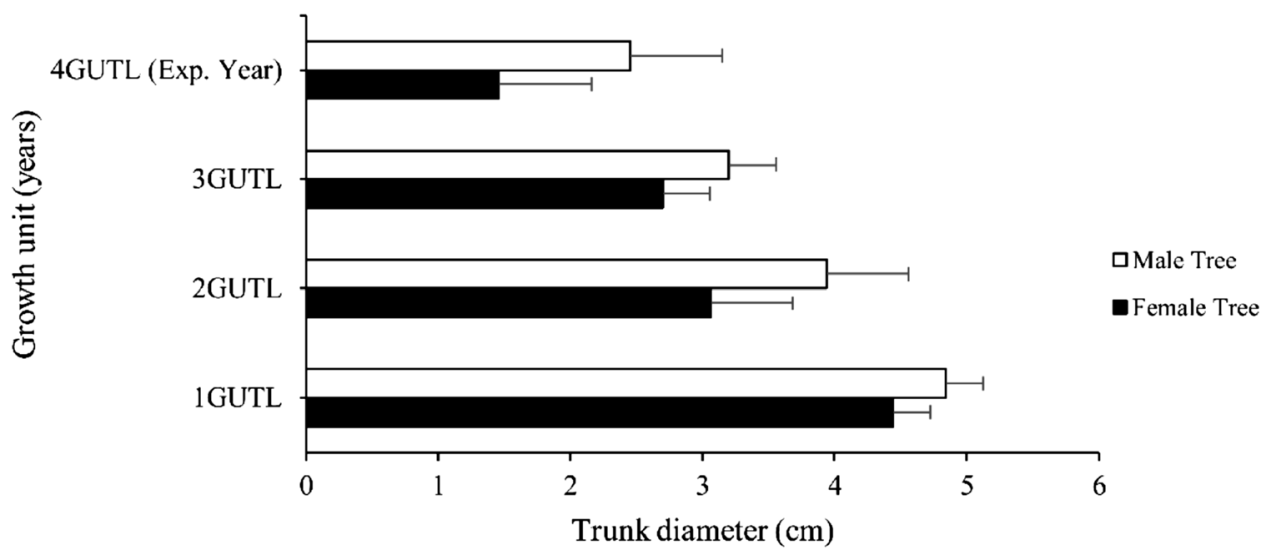

Fig. 3 Trunk diameter at different years. The mean trunk diameter at different ages was calculated from young female and male I. polycarpa trees. The different sections indicated different year growth unit, the indication for both sexes, respectively. Significant differences not exhibited when the whole stem diameter (i.e. 1GUTD, 2GUTD,
3GUTD) compared between females and male sexes; $P=0.419$. Data values represent the mean $\pm \mathrm{SD}$. $1 G U T D$ first year growth unit trunk diameter, $2 G U T D$ second year growth unit trunk diameter, 3GUTD third year growth unit trunk diameter 


\section{Short branch growth variation}

The annual growth also affects the short branches, situated on the long branches, which increased in length and diameter with small increments compared to the long branches. The young male trees produced significantly higher numbers of short branches from the different tier of branches than for young female trees. The young male trees $1 Y$ produced seven, the $2 \mathrm{Y}$ produced six, and the $3 \mathrm{Y}$ produced two short branches. The female trees produced the less significant number of short branches, the $1 \mathrm{Y}$ produced five, the $2 \mathrm{Y}$ produced five, and the $3 \mathrm{Y}$ produced of one short branch (Fig. 5). Most of the flowering and fruiting occurs directly on the short branches. The production of the yield mostly depended on the short and the tertiary branches.

\section{Length and diameter of extended long-branch sections in the different tire of branches among preceding years}

During the growth from a static state of the study trees of I. polycarpa, the branch extended the length and diameter through the year and increased by a particular length and diameter each growing year. A comparison was made between young female and male I. polycarpa trees. The branch length and diameter of the $1 \mathrm{Y}$ encompassed growth in the 1BS, 2BS, 3BS, and 4BS (grow in study year). The branch length and diameter of the $2 \mathrm{Y}$ encompassed growth in the 2BS, 3BS, and 4BS. The branch length and diameter of the $3 \mathrm{Y}$ encompassed the $3 \mathrm{BS}$ and $4 \mathrm{BS}$. The continued upward growth observed in the male trees, contrariwise the upward and the downward growth observed in the female trees of the branch length static state condition. The diameter growth followed the same trend as the length of both sexes. The differences in the branches grow of the length and diameter are shown in the figure (Figs. 6,7).

\section{Annual dynamic growth of shoots sprouted from terminal buds of different tier of branches}

The newly sprouted LTB of $3 Y$ of the female tree grew rapidly from the beginning of the sprouting season whereas the LTB's of $2 Y$ and 1Y's grew slowly throughout the growing year. The newly sprouted LTB of $3 \mathrm{Y}$ grew to their maximum length, meanwhile, the newly sprouted TB of the female tree has greatly increased the diameter along with the greatest number of leaves in the new growing year.
Fig. 4 Number of the long branches. Mean numbers of long branches differences, long branches are distributed all around the trunk on successive leaves constituting a tier of branches of the different year's growth unit. Data values represent the mean \pm SD

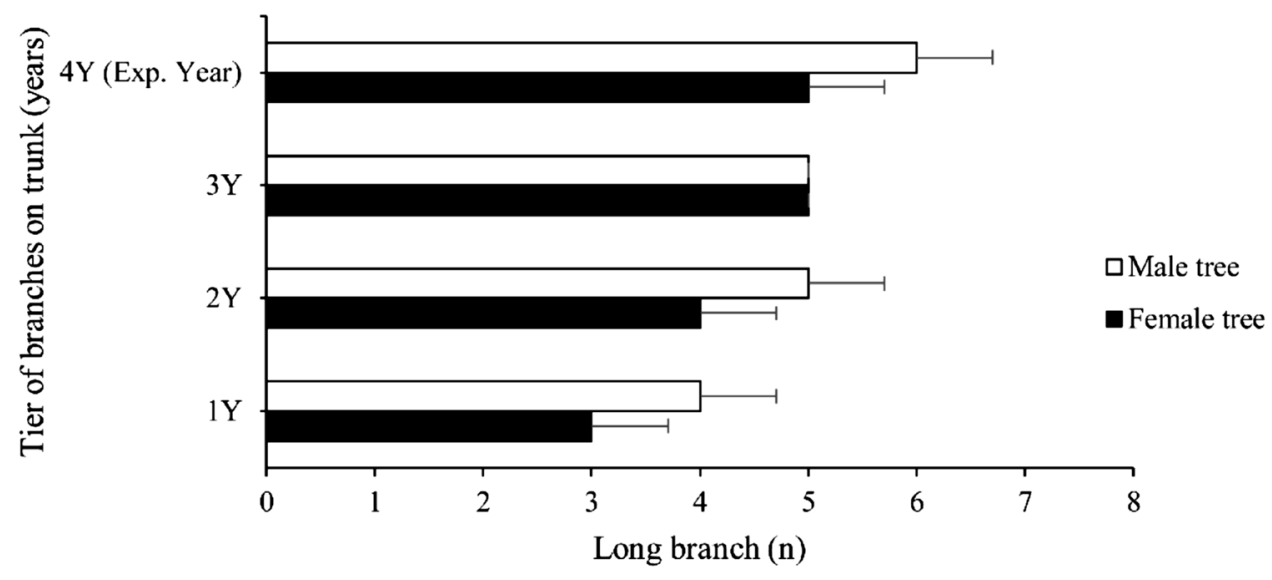

Fig. 5 Number of the short branches. Mean numbers of short branches differences, located on different branch sections of the different tier of branches. Data values represent the mean \pm SD

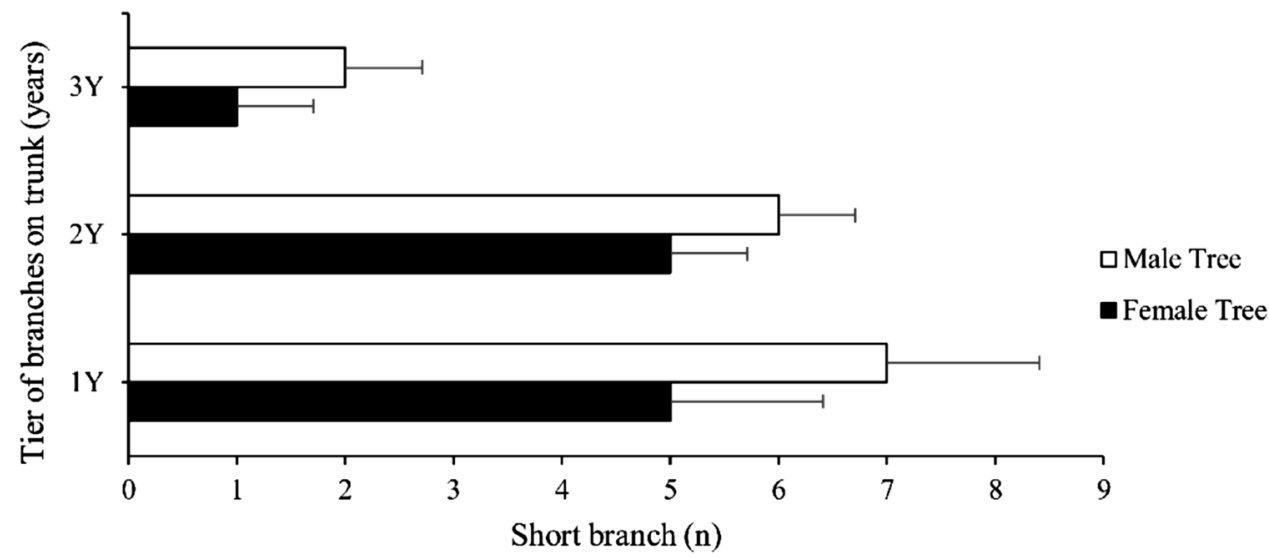




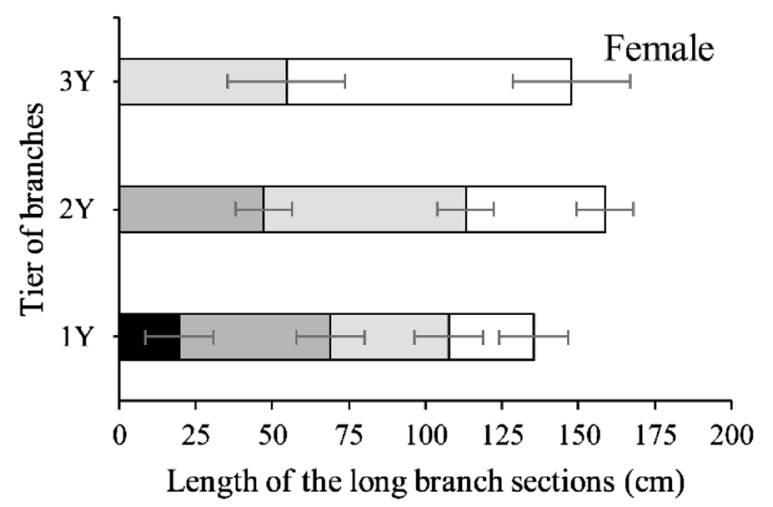

Fig. 6 Length of extended long-branch sections in the different tire of branches among preceding and current year. Differences of the extended section of branches, comparison between sexes. The indica-

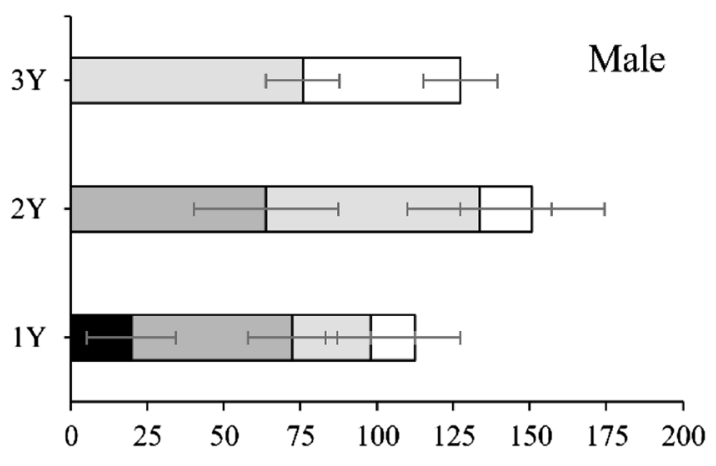

tion for both of the female and male trees, respectively. Data values represent the mean $\pm \mathrm{SD}$

- 1BS 口2BS $\square 3 \mathrm{BS} \quad \square 4 \mathrm{BS}$ (Exp. Year)
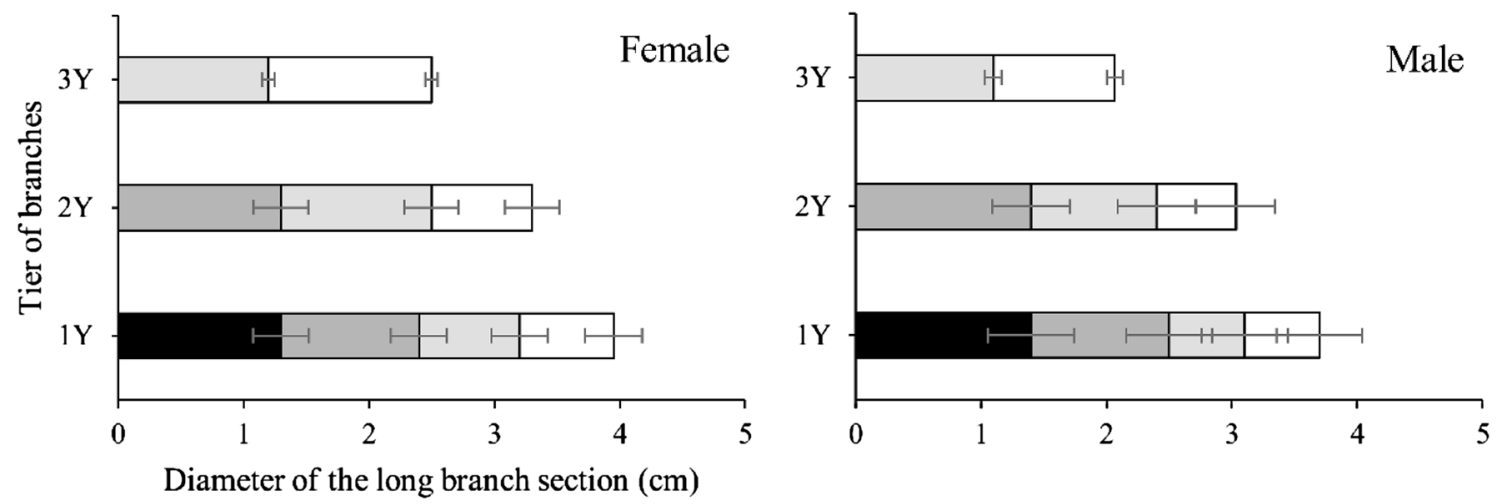

Fig. 7 Diameter differences of extended long branch sections. Differences in diameter between sexes, the sections of long branches of the tier of branches. The indication for both of the female and male trees, respectively. Data values represent the mean $\pm \mathrm{SD}$

\section{The quantitative values of newly sprouted terminal buds length extension in the female and male plants}

The newly sprouted terminal buds length of female trees increased during the growing year; the TB increased by $79.85 \mathrm{~cm}$, the LTB of $3 Y$ by $93.1 \mathrm{~cm}$, the LTB of $2 \mathrm{Y}$ by 45.5 , and the LTB of $1 \mathrm{Y}$ by $27.6 \mathrm{~cm}$. Besides, the male trees the newly sprouted TB increased by $56.73 \mathrm{~cm}$, the LTB of 3Y by $51.4 \mathrm{~cm}$, the LTB of $2 \mathrm{Y}$ by $17.1 \mathrm{~cm}$, and the LTB of $1 \mathrm{Y}$ by $14.5 \mathrm{~cm}$. The TB length was significantly greater in females than males (mean $\pm \mathrm{SD}=49.84 \pm 25.68$ and $36.96 \pm 16.45 \mathrm{~cm}$ for females and males, respectively; $P=0.199$ ). The LTB of Y3 length (mean $\pm \mathrm{SD}=57.54 \pm 29.95$ and $34.07 \pm 14.41 \mathrm{~cm}$ for females and males, respectively; $P=0.039$ ). The LTB of $2 \mathrm{Y}$ length (mean $\pm \mathrm{SD}=31.17 \pm 12.92$ and $12.56 \pm 3.71$ for females and males, respectively; $P<0.001$ ) and the LTB of
$1 Y$ length (mean $\pm \mathrm{SD}=20.52 \pm 6.66$ and $10.86 \pm 2.91$ for females and males, respectively; $P=0.001$ ).

\section{Diameter growth of newly sprouted terminal buds female and male plants}

The mean diameter of the newly sprouted buds of female trees increased during the growing year; the diameter of the TB was $1.7 \mathrm{~cm}$, while those LTB of $3 Y 1.3 \mathrm{~cm}$, LTB of $2 Y 0.8 \mathrm{~cm}$, and LTB of $1 Y 0.8 \mathrm{~cm}$, respectively. Contrariwise, the male tree the mean increase in diameter of TB was $1.3 \mathrm{~cm}$, LTB of $3 Y 1.0 \mathrm{~cm}$, LTB of $2 \mathrm{Y}$ $0.6 \mathrm{~cm}$, and LTB of $1 \mathrm{Y} 0.6 \mathrm{~cm}$, respectively. The TB diameter growth were significantly greater in females than males (mean $\pm \mathrm{SD}=1.14 \pm 0.37$ and $0.94 \pm 0.25$ for females and males, respectively; $P=0.181$ ). The 
LTB of $3 \mathrm{Y}($ mean $\pm \mathrm{SD}=0.94 \pm 0.27$ and $0.8 \pm 0.16$ for females and males, respectively; $P=0.081$ ). The LTB of $2 \mathrm{Y}($ mean $\pm \mathrm{SD}=0.64 \pm 0.12$ and $0.52 \pm 0.08$ for females and males, respectively; $P=0.018$ ). The LTB of $1 \mathrm{Y}$ (mean $\pm \mathrm{SD}=0.60 \pm 0.10$ and $0.50 \pm 0.07$ for females and males, respectively; $P=0.027$ ).

\section{Leaf production of newly sprouted terminal buds of female and male plants}

Newly sprouted TB of the female tree produced the maximum mean number of leaves; the mean number of the leaves produced by female trees during the growing year was 157 from the newly sprouted TB, 97 from the LTB of $3 \mathrm{Y}, 44$ from the LTB of $2 \mathrm{Y}$, and 34 from the LTB of $1 Y$. Contrariwise, the mean number of leaves produced by male trees during the growing year was 138 from the TB, 65 in the LTB of $3 Y, 25$ in the LTB of $2 Y$, and 21 in the LTB of 1Y. Leaves were produced throughout the experimental year, and were leaf census from the newly sprouted TB, along with the LTB's tier of branches. The TB leaf production was significantly greater in females than for the males (mean $\pm \mathrm{SD}=89.70 \pm 48.03$ and $67.50 \pm 47.16$ for females and males, respectively; $P=0.311)$. The LTB of $3 \mathrm{Y}($ mean $\pm \mathrm{SD}=55.80 \pm 30.69$ and $42.00 \pm 19.24$ for females and males, respectively; $P=0.244$ ). The LTB of $2 \mathrm{Y}$ (mean $\pm \mathrm{SD}=27.80 \pm 11.33$ and $17.60 \pm 6.22$ for females and males, respectively; $P=0.023$ ). The LTB of $1 \mathrm{Y}($ mean $\pm \mathrm{SD}=22.90 \pm 8.23$ and $15.20 \pm 4.59$ for females and males, respectively; $P=0.019$ ).

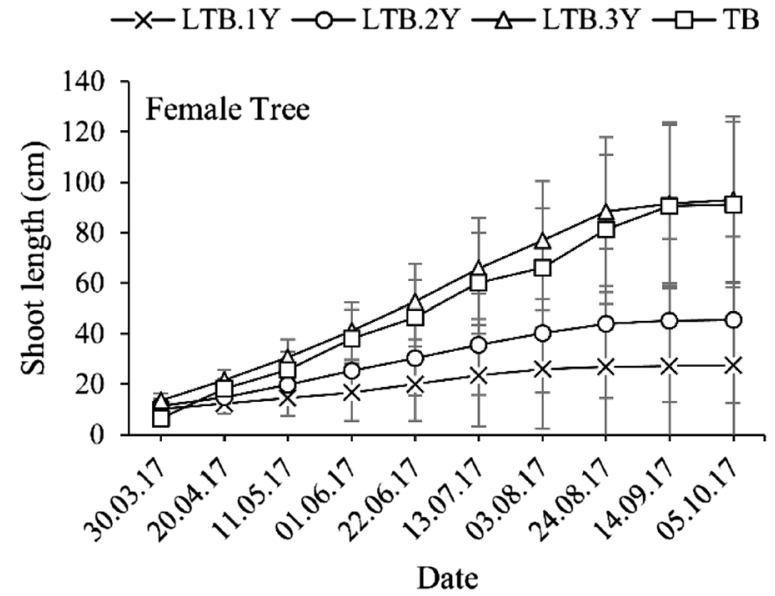

Fig. 8 Lengths of newly sprouted TB and LTB's, showing shoot growth after the sprouting of terminal buds, and shoot length increases over time. The solid lines show the shoot growth length over time, asterisk symbol indicated the growth of the LTB of 1Y, circles indicated LTB of $2 \mathrm{Y}$, triangles indicated LTB of $3 \mathrm{Y}$, and squares
Length extension comparison among TB and LTB extension

The maximum lengths of the newly sprouted LTB of the $3 Y$ increased in the female trees, but the lengths of the LTB of the $1 \mathrm{Y}$ of male trees increased minimally, highly significance in maximum LTB.3Y and least LTB.1Y length of females, respectively; $P<0.001$ (Fig. 8). The LTB of the $3 \mathrm{Y}$ of female trees grew in length by more than other LTB of the tire of branches. The LTB of $3 Y$ and LTB of $2 \mathrm{Y}$ females were obtained the significance $P=0.008$, and the great significance observed in the LTB of $3 Y$ and LTB of $1 Y P<0.001$. Whereas the LTB of the $2 Y$ and LTB of $1 \mathrm{Y}$ significance $P=0.265$ did not differ much in length. The lengths of the newly sprouted LTB of the $3 \mathrm{Y}$ and the newly sprouted TB significance $P=0.419$ are similar, but not identical. Contrariwise, the male trees, the newly sprouted TB were higher than other newly sprouted LTB. The LTB of $3 \mathrm{Y}$ and LTB of $2 \mathrm{Y}$ males showed the high significance $P<0.001$, and the significance observed in the LTB of $3 \mathrm{Y}$ and LTB of $1 Y$ of males $P<0.001$. Whereas the differences in length of the newly sprouted LTB of the $2 \mathrm{Y}$ and LTB of 1Y $P=0.736$ was slight. The LTB of $3 Y$ and the length of the TB of newly sprouted exhibited differences $P=0.500$ in growth throughout the growing year.

\section{Diameter growth comparison among TB and LTB extension}

The maximum mean diameter obtained the newly sprouted TB of the female trees, and the minimum mean diameter obtained the newly sprouted LTB of $1 \mathrm{Y}$ of the male trees (Fig. 9). The TB of the female tree had the greatest increase in diameter, and there were considerable differences among

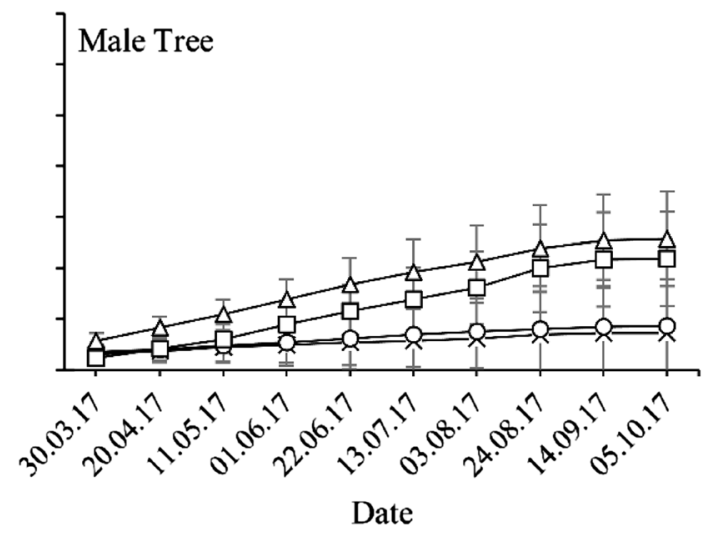

indicated TB of the tree, female and male tree respectively (the significant differences of length extension in newly sprouted shoots of females and males were observed; $P=0.199$ for TB, $P=0.039$ LTB of Y3, $P<0.001 \mathrm{LTB}$ of $2 \mathrm{Y}$ and $P<0.001 \mathrm{LTB}$ of $1 \mathrm{Y}$ ). Data values represent the mean $\pm \mathrm{SD}$ 
the newly sprouted TB and LTB of the $2 \mathrm{Y}$ significance; $P<0.001$, TB and LTB of $1 Y$ showed the significant differences; $P<0.001$. There are no significant differences observed between the diameters of the LTB of the $2 \mathrm{Y}$ and $1 Y$ were $P=0.679$. The newly sprouted TB and the LTB of the $3 \mathrm{Y}$ differed in diameter and the significant differences were $P=0.072$. While, the male trees, the newly sprouted TB had the greatest increase in diameter during the growing year. Whereas the rest of the newly sprouted LTB had less of an increase. The newly sprouted TB and LTB of the $2 Y$ showed the considerable significance differences; $P<0.001$, In the TB and LTB of $1 Y$ exhibited the significance of differences; $P<0.001$. LTB of $2 \mathrm{Y}$ and LTB of the $1 \mathrm{Y}$ of males have no significant differences; $P=0.777$. In the newly sprouted TB and LTB of the $3 Y$ exhibited the significance of differences in diameter growth; $P=0.012$.

\section{Comparison of leaf production among TB and LTB extension}

Leaves play a vital role in the shape's development and structure of the tree. The newly sprouted TB of the female tree produced the maximum number of leaves during the growing year, but the male trees produced the least leaves from the newly sprouted LTB of the 1Y (Fig. 10). The female tree produces the maximum mean number of leaves in the TB, and the differences obvious among the TB and the LTB of the $2 \mathrm{Y}$ showed the highly significant difference; $P<0.001$, along TB and LTB of $1 \mathrm{Y}$ are considerable; $P<0.001$, whereas in the newly sprouted LTB of the $2 \mathrm{Y}$ and the $1 \mathrm{Y}$; $P=0.710$ there was no significance. The newly sprouted TB and LTB of the $3 \mathrm{Y}$ exhibited less significance value;

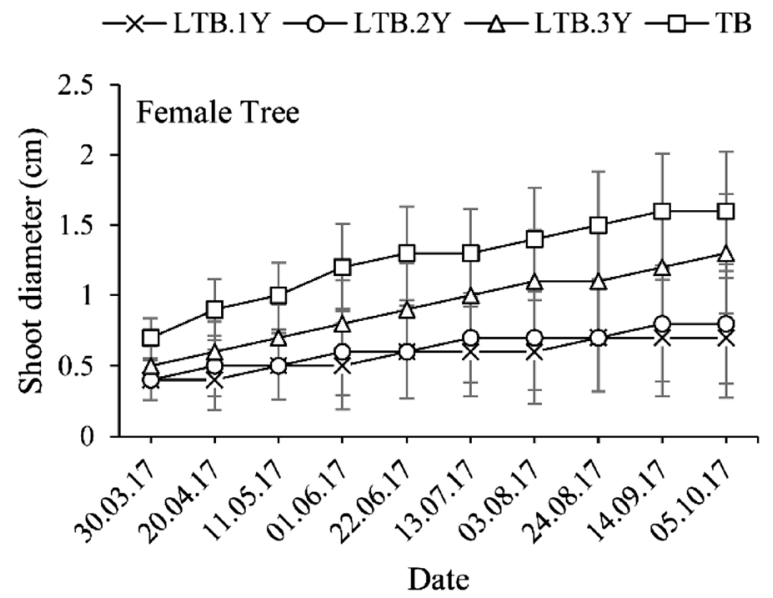

Fig. 9 Diameter differences in newly sprouted TB and LTB, sprouted shoot diameter increased over time for both female and male trees. The solid lines show the diameter of shoot growth over time, asterisk symbol indicated the growth of the LTB of 1Y, circles indicated LTB of $2 \mathrm{Y}$, triangles indicated LTB of $3 \mathrm{Y}$, and squares indicated TB of the
$P=0.014$. Contrariwise, the male trees, the mean number of leaves was highest in the newly sprouted TB, whereas the newly sprouted TB and LTB of the $2 \mathrm{Y}$ showed the higher significance value; $P<0.001$, similarly TB and LTB of $1 \mathrm{Y}$ exhibited high significant differences; $P<0.001$, produced similar amounts of leaves. In LTB of $2 \mathrm{Y}$ and LTB of $1 \mathrm{Y}$ has not exhibited the significant differences; $P=0.843$. The newly sprouted TB and LTB of the $3 Y$ showed less significant for leaf production; $P=0.033$.

\section{The variation of DBH during annual growth}

The cumulative growth of DBH through the growing year, the variation observed different dates and the values compared between sexes. The females and male trees DBH growth pattern showed the differences, the DBH growth rate and the timing were significantly differenced. The male trees annual DBH growth reached the greatest values throughout the growing year. The gradual DBH growth observed from the 14-April, the continuous upward trend that can be seen in 29-May, and the value decline observed in 13-June. The highly significance upward trend observed from 28-June and the greatest value reached in 13-July. The declining value and risen value can be observed from July to September, and the downward trend value recorded in October. The fastest DBH growth in the male tree occurs from near end of the June to the beginning of the September months, the male's DBH growth occurs the quickest time than for the female trees. The highest DBH value achieved on 13-July $(0.9 \pm 0.03 \mathrm{~cm}$, mean $\pm \mathrm{SE}, n=22)$ and the least value recorded on 30 -March $(0.02 \pm 0.004 \mathrm{~cm}$, mean $\pm \mathrm{SE}, n=22)$ in the male trees during the growing year. Contrariwise, the

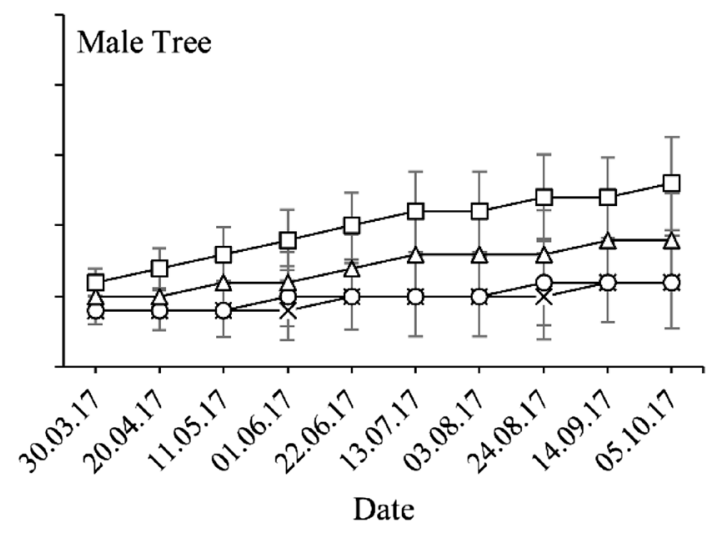

tree, female and male tree, respectively (the significant differences of growth diameter in newly sprouted shoots of females and males were observed; $P=0.181$ for TB, $P=0.081$ LTB of $3 Y, P=0.018$ LTB of $2 \mathrm{Y}$ and $P=0.027 \mathrm{LTB}$ of $1 \mathrm{Y}$ ). Data values represent the mean $\pm \mathrm{SD}$ 

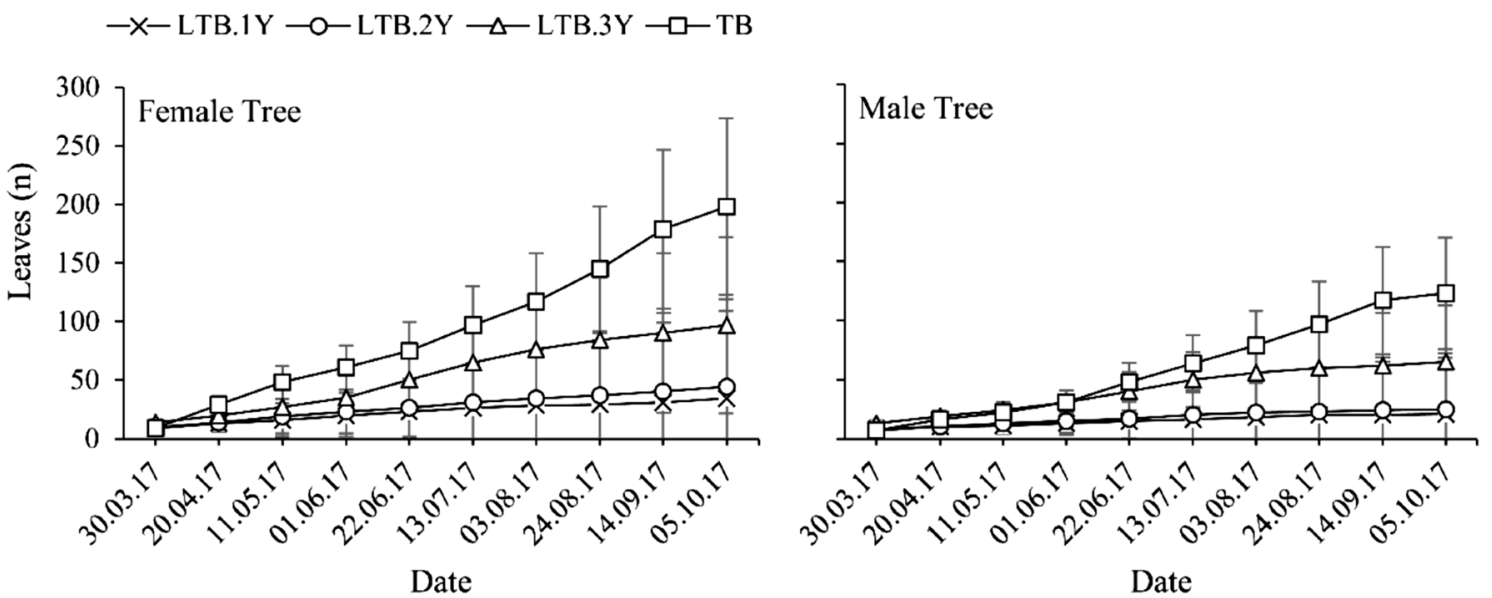

Fig. 10 Leaf number production among TB and LTB's. Differences in production of leaf number between female and male trees in the newly sprouted TB and LTB entire the growing year. The solid lines show the number of the leaves on shoot growth over time, asterisk symbol indicated the growth of the LTB of 1Y, circles indicated LTB

female trees cumulative DBH growth occurs with longer periods. The growth observed from the 30-March, upward and downward value trend obvious from 29-May. The notable DBH value observed from 13-June to the 11-October. The fastest growth observed in June-13, decline value recorded in 13-July, the second-fastest value recorded from the end of July to the end of the September months. The highest DBH value recorded in $13-J u n e ~(0.07 \pm 0.01 \mathrm{~cm}$, mean $\pm \mathrm{SE}, n=22$ ) and the least value recorded in 26-October $(0.01 \pm 0.003 \mathrm{~cm}$, mean $\pm \mathrm{SE}, n=22)$ in the female trees during the annual growth (Fig. 11).

\section{Discussion}

In the females, the expansion of the length, and diameter of TB, LTB, and leaf production of the current growing year, the trunk length of the preceding years was higher than males. The growth of length and diameter of the longbranch sections demonstrate the upward and downward trend followed in females. In the males, the trunk length, and diameter of the current growing year, the preceding years of trunk diameter, the production of long and short branches was higher than females. The growth of the length, diameter of the long-branch sections, the upward trend followed in males.

In addition, the trunk growth increased in length and diameter during the growing year, to develop the structure and shape of the tree. The recorded data of the trees observed in this study explained the differences in growth length and diameter between the female and male trees of I. polycarpa in different years. The growth unit of the trunk of $2 \mathrm{Y}$, triangles indicated LTB of $3 \mathrm{Y}$, and squares indicated TB of the tree, female and male tree, respectively (the significant differences of leaf production in newly sprouted shoots of females and males; $P=0.311$ for TB, $P=0.244$ LTB of Y3, $P=0.023$ LTB of $2 \mathrm{Y}$ and $P=0.019$ LTB of 1 Y). Data values represent the mean \pm SD

length and diameters growth fluctuation rate was observed from the earlier years. Additionally, the production of the tier of branches associated with annual growth, arising from the newly sprouted TB. During the sprouting season from the TB several long branches are formed and the number is random. The males growing larger numbers of long branches than the females, and these numbers are highly significant for the further development of the tree as vegetative, as well as reproductive, whereas short branches developed from various locations on the long branches. However, short branches grew in high numbers on the male trees. The development of short branches was associated with the growing year. They directly correlated with flowering and fruit production (fruiting for females), with most of flowering and fruit sections occurring on short branches. Annual growth also effects on the length and diameter of short branches. For male young trees, their $1 \mathrm{Y}$ produced more short branches, compared to others, including sexes. Furthermore, the growth from a static state of young trees of I. polycarpa, the study showed differences in the growth length and diameter of the various sections of the branch of the tire of branches from preceding years that increased during that growing year. The preceding year's growth units indicated that the earlier years growth and development of the plant.

The selected trees both of the sexes exhibited distinctly different growth rates during the growing year, and the newly sprouted TB and LTB of the tier of branches exhibited considerable variability regarding length extension, diameter growth, and leaf production. This considerable variation may explain the differences in annual growths aim of the TB of each tree and the LTB of the tier of branches. It is likely that I. polycarpa also has a physiological disparity between 


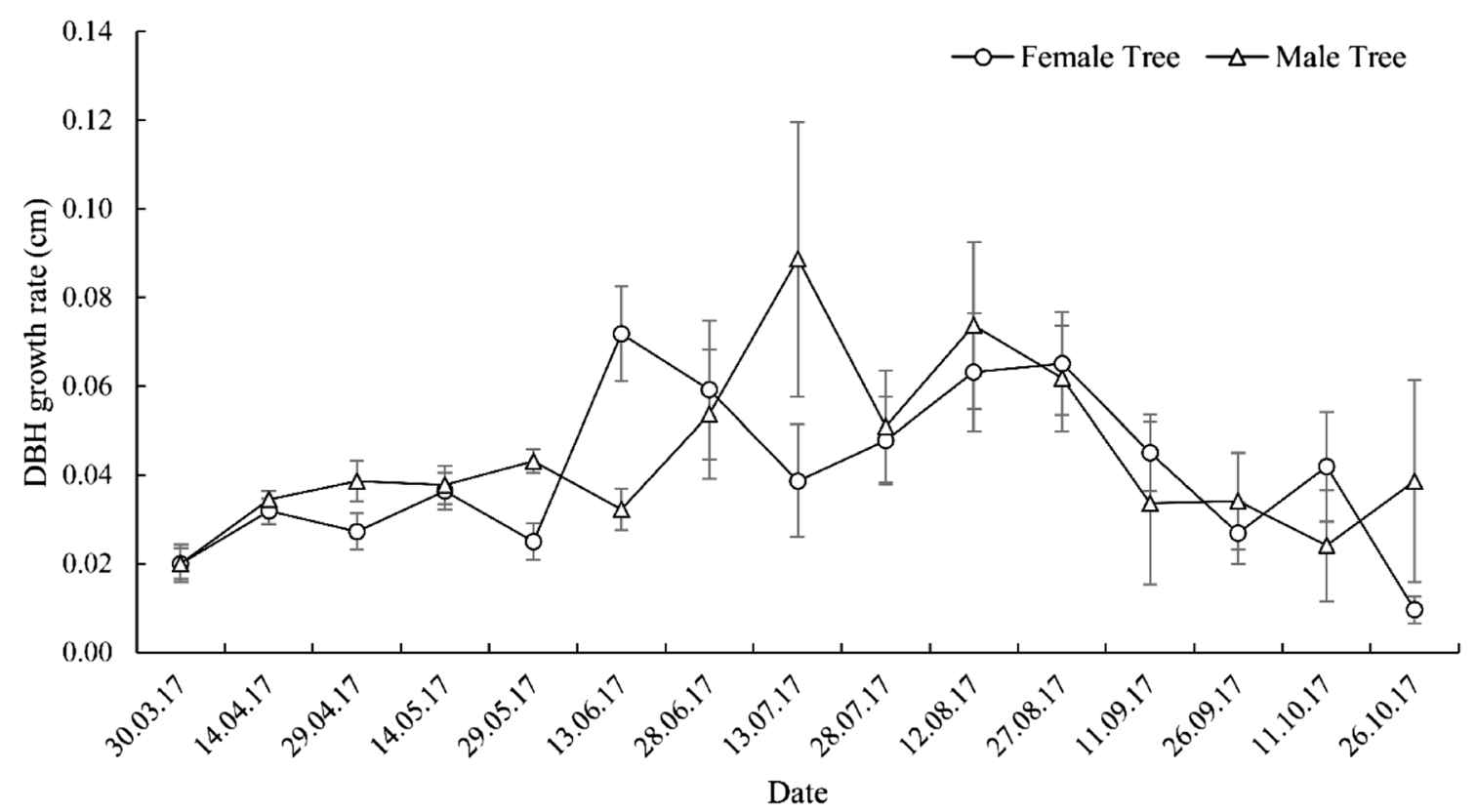

Fig. 11 The cumulative growth of diameter at breast height (DBH) throughout the annual growth, the comparison made with females and male trees. The male's DBH increment occurs in the short periods, whereas female increases with longer periods. In the month of June, the females reached the highest growth rate, whereas the males are in July. The higher rate of the DBH occurs during each June to August months of the year

increment of diameter observed in TB of females and least observed in LTB-1Y of males.

Alongside, a higher total number of leaf primordia particularly in females and turn to greater vegetative biomass production. The pre-defined size threshold of leaves depends on the tree species. Leaves spiral around the branch at a set interval and with randomized orientations. The leaf growth rate has often been reported to be positively related to leaf nitrogen and assimilation rates (Poorter and Bongers 2006), negative relationships between leaf thickness and growth rates have been observed by (Nielsen et al. 1996 and Poorter 1989). Constructing toughened leaves is a way of protecting them physically from external agents (Westbrook et al. 2011), in particular from desiccation (Díaz et al. 2004), herbivores (Dominy et al. 2008), and pathogens (Hantsch et al. 2014). Our studies of I. polycarpa found that the number of the leaves produced on newly sprouted TB and the LTB of $1 \mathrm{Y}, 2 \mathrm{Y}$ and $3 \mathrm{Y}$ of female tree were higher than for the male trees, for the TB and the LTB of the different tier of branches, and the leaf size, and weight differences also observed in the different tier of branches (data not shown). The growth was much faster in the relatively wet and warm season than the relatively dry and cold season for all trees with varying leaf habits. In the growing year, the rate of newly sprouted shoot growth was higher in the warmer months, when the temperature was higher, from May to August. As the temperature rose the rate of sprouted shoot 
growth gradually increase and as the temperature fell the rate was slower and slower.

However, the diameter at breast height (DBH) and cumulative growth throughout the year between the sexes, the males attained the greatest DBH increment. The male's DBH increment occurs in the short periods, whereas female increases with longer periods. In the month of June, the females reached the highest growth rate, whereas the males are in July. The higher rate of the DBH occurs during each June to August months of the year in young I. polycarpa trees. The variation of the DBH throughout the annual growth occur at "slow-fast-slow" rate.

The growth pattern in young trees of the deciduous species I. polycarpa showed that the growth of females exceeded that of males, in terms of length extension, diameter growth, and leaf production in the growing year. In contrast, the sexes differed in terms of vegetative growth patterns, with males producing more long and short branches than females. Besides, the stem-diameter and the variation of the diameter at breast height was higher in males. The analysis of the allocation of biomass in the crown architecture and the branching structure estimation, need to further investigation.

The shoot growth process of the newly sprouted terminal bud of the tree and the LTB buds of the different tier of branches showed the variation of the length and diameter elongation throughout the growing year of female and male sexes of young I. polycarpa trees. The studies emphasized the annual vegetative growth and examined the pattern of the variation in vegetative growth compared to sexual dimorphism.

We conclude that during the growing year, the TB and LTB of the tier of branches sprouted and the growth of the female trees exceeded that of males, In terms of TB, LTB of length extension, diameter growth, and leaf production and the sexes differed in terms of vegetative growth pattern. In addition, the studies compared the production of long and short branches. Males produce considerably higher numbers of long and short branches than female trees. A new tier of branches formed into the TB in every growing year and continued the growth and development of the long and short branches for developing the crown formation of the tree. However, the growth unit of trunk length showed a clear regression in annual trunk length extension of the females, while the males showed the opposite. In contrast, the male trees showed a significant of height growth of trunk diameter, production of long branches, and short branches. The highest growth rate observed in I. polycarpa when the temperature was above $20{ }^{\circ} \mathrm{C}$ (minimum) and below $36{ }^{\circ} \mathrm{C}$ (maximum). This study of the annual shoot growth processes shows growth differences and comparisons between sexes in terms of annual vegetative growth. This study also reveals how annual growth influences the development of the young dioecious tree. Further investigation is required to identify if there are any long-term gender-related differences present in the shoot growth or not.

Author contribution statement Study conception and design: SR, LZ. Acquisition of data: SR. Analysis and interpretation of data: SR. Drafting of manuscript: SR, LZ. Critical revision: LZ.

Funding Forestry science and technology development project, science and technology development center of national forestry and grassland administration. The grant number: KJZXSA2019041. Recipient: Liu Zhen.

\section{Compliance with ethical standards}

Conflict of interest The authors declare that they have no conflict of interest exists.

Open Access This article is licensed under a Creative Commons Attribution 4.0 International License, which permits use, sharing, adaptation, distribution and reproduction in any medium or format, as long as you give appropriate credit to the original author(s) and the source, provide a link to the Creative Commons licence, and indicate if changes were made. The images or other third party material in this article are included in the article's Creative Commons licence, unless indicated otherwise in a credit line to the material. If material is not included in the article's Creative Commons licence and your intended use is not permitted by statutory regulation or exceeds the permitted use, you will need to obtain permission directly from the copyright holder. To view a copy of this licence, visit http://creativecommons.org/licenses/by/4.0/.

\section{References}

Bochenek GM, Eriksen B (2010) Annual growth of male and female individuals of the Common Ash (Fraxinus excelsior L.). Plant Ecol Divers 3:47-57. https://doi.org/10.1080/17550 874.2010.490278

Charlesworth D (2016) Plant sex chromosomes. Annu Rev Plant Biol 67:397-420. https://doi.org/10.1146/annurev-arplant-04301 $5-111911$

Davidson CG, Remphery WR (1990) An analysis of architectural parameters of male and female Fraxinus pennsylvanica in relation to crown shape and crown location. Can J Bot 68:2035-2043. https://doi.org/10.2307/3243528

Dawson TE, Ehleringer JR (1993) Gender-specific physiology, carbon isotope discrimination, and habitat distribution in box elder, Acer negundo. Ecology 74:798-815. https://doi.org/10.2307/1940807

Díaz S, Hodgson JG, Thompson K, Cabido M, Cornelissen JHC, Jalili A, Montserrat-Marti G, Grime JP, Zarrinkamar F, Asri Y (2004) The plant traits that drive ecosystem: evidence from three continents. J Veg Sci 15:295-304. https://doi. org/10.1111/j.1654-1103.2004.tb02266.x

Dominy N, Grubb P, Jackson R, Lucas P, Metcalfe D, Svenning J, Turner I (2008) In tropical lowland rain forests monocots have 
tougher leaves than dicots, and include a new kind of tough leaf. Ann Bot 101:1363-1377. https://doi.org/10.1093/aob/mcn046

Dudley LS (2006) Ecological correlates of secondary sexual dimorphism in Salix glauca (Salicaceae). Am J Bot 93:1775-1783. https ://doi.org/10.3732/ajb.93.12.1775

Glawe GA, de Jong TJ (2009) Complex sex determination in the stinging nettle Urtica dioica. Evol Ecol 23:635-649. https://doi. org/10.1007/s10682-008-9261-5

Grant MC, Mitton JB (1979) Elevational gradients in adult sex ratios and sexual differentiation in vegetative growth rates of Populus tremuloides Michx. Evolution 33:914-918. https://doi. org/10.1111/j.1558-5646.1979.tb04744.x

Hantsch L, Braun U, Haase J, Purschke O, Scherer-Lorenzen M, Bruelheide $H$ (2014) No plant functional diversity effects on foliar fungal pathogens in experimental tree communities. Fungal Divers 66:139-151. https://doi.org/10.1007/s13225-013-0273-2

Huang S, Titus SJ, Wiens DP (1992) Comparison of nonlinear heightdiameter functions for major Alberta tree species. Can J Forest Res 22:1297-1304. https://doi.org/10.1139/x92-172

Jia R-R, Tang X-S, Dong N, Tang L, Chen F (2014) Influence of different mature degrees on seeds germination and quality of Fruit oil of Idesia polycarpa maxim. var. vestita Diels. Seed 33:38-41 (in Chinese with English summary). http://en.cnki.com.cn/Artic le_en/CJFDTotal-ZHZI201409010.htm

Jun FS, Wei Sheng S, Wu Nong L (2004) A study on the preservative technique of shuidonggua seeds at room temperatures. Journal of Northwest Forestry University 19:64-65. (in Chinese with English summary) http://en.cnki.com.cn/Article_en/CJFDTOTALXBLX200401018.htm

King DA (1990) The adaptive significance of tree height. Am Nat 135:809-828. https://doi.org/10.1086/285075

Liu GL, Liang ZH, Jiang ZP (2005) Review on the research of Idesia polycarpa. Jiangsu For Sci Technol 32:46-49 (in Chinese with English summary). http://www.wanfangdata.com.cn/details/detai 1.do?_type=perio\&id=jslykj200505012

Mayer WH (1936) Height curves for even-aged stands of Douglas-fir. US For. Serv. Pacif. Nthwest. For. and Range Expt. Stat

Nielsen S, Enriquez S, Duarte C, Sand-Jensen K (1996) Scaling maximum growth rates across photosynthetic organisms. Funct Ecol 10:167-175. https://doi.org/10.2307/2389840

Picard JF (1982) Contribution to the study of flowering and fruiting in the common ash (Fraxinus excelsior). [Contribution à l'étude de la biologie florale du frêne et de la fructification du frene commun (Fraxinus excelsior L.).] Revue Forestiere Francaise 34:97-107; 2 pl.; 16 ref

Poorter H (1989) Interspecific variation in relative growth rates: on ecological causes and physiological consequences. Causes and consequences of variation in growth rate and productivity of higher plants. SPB Academic Publishing, The Hague, pp 45-68

Poorter L, Bongers F (2006) Leaf traits are good predictors of plant performance across 53 rain forest species. Ecol Wallander 87:17331743. https://doi.org/10.1890/0012-9658(2006)87\%5b173 3:LTAGPO $\% 5 \mathrm{~d} 2.0 . \mathrm{CO} ; 2$

Ren C (1995) Utilization of oleic acid. Daily Chemical Industry 000(002):53-55 (in Chinese with English summary). http:// kns.cnki.net/KCMS/detail/detail.aspx ?dbcode $=$ CJFD\&filen ame $=$ CHEM502.016
Renton M, Guédon Y, Godin C, Costes E (2006) Similarities and gradients in growth unit branching patterns during ontogeny in 'Fuji' apple trees: a stochastic approach. J Exp Bot 57:3131-3143. https ://doi.org/10.1093/jxb/er1075

Rozas V, DeSoto L, Olano JM (2009) Sex-specific, age-dependent sensitivity of tree-ring growth to climate in the dioecious tree Juniperus thurifera. New Phytol 182:687-697. https://doi.org/10 $.1111 / \mathrm{j} .1469-8137.2009 .02770 . x$

Sakai AK, Burris TA (1985) Growth in male and female aspen clones: a twenty five year longitudinal study. Ecology 66:1921-1927. https://doi.org/10.2307/2937388

Sakai AK, Sharik TL (1988) Clonal growth of male and female bigtooth aspen (Populus grandidentata). Ecology 69:2031-2033. https://doi.org/10.2307/1941181

Shannon R, Holsinger K (2007) The genetics of sex determination in stinging nettle (Urtica dioica). Sex Plant Reprod 20:35-43. https ://doi.org/10.1007/s00497-006-0041-5

Wallander E (2001) Evolution of wind pollination in Fraxinus (Oleaceae): en ecophylogenetic approach, $\mathrm{PhD}$ thesis. Göteborg University, Göteborg

Wang YM, Wang DH, Liu Z, Wang L, Jing ZJ, Dai L (2011) Analysis of oil content and fatty acid GC/MS in Idesia polycarpa seeds from different provenances. J Henan Agric Univ 45:1-6 (in Chinese with English summary)

Wang YM, Li F, Cai QF, Dai L, Huang S, Ma TX, Liu Z (2014) The ISSR inheritance difference analysis of Idesia polycarpa in different distribution areas. J Henan Agric Univ 48:706-712 (in Chinese with English summary)

Westbrook J, Kitajima K, Burleigh J, Kress W, Erickson D, Wright S (2011) What makes a leaf tough? Patterns of correlated evolution between leaf toughness traits and demographic rates among 197 shade-tolerant woody species in a neotropical forest. Am Nat 177:800-811. https://doi.org/10.1086/659963

Willson MF (1986) On the costs of reproduction in plants: Acer negundo. Am Mid Nat 115:204-207. https://doi. org/10.2307/2425852

Yang Z (2001) Study on several wild woody oil crops with reference to their economic values. Econ Forest Res 19:36-37 (in Chinese with English summary). http://www.wanfangdata.com.cn/detai 1s/detail.do?_type=perio\&id=jjlyj200104015

Yang FX, Su YQ, Li XH, Zhang Q, Sun RC (2009) Preparation of biodiesel from Idesia polycarpa var. vestita fruit oil. Ind Crops Prod 29:622-628. https://doi.org/10.1016/j.indcrop.2008.12.004

Zhang C, Zhao X, Gao L, Gadow K (2009a) Gender, neighboring competition and habitat effects on the stem growth in dioecious Fraxinus mandshurica trees in a northern temperate forest. Ann Forest Sci 66:812. https://doi.org/10.1051/forest/2009068

Zhang Z, Luo X, Yang L (2009b) Exploitage of Idesia polycarpa oil. Cereals Oils Food Technol 06:28-30 (in Chinese with English summary). http://www.wanfangdata.com.cn/details/detail.do? type $=$ perio\&id $=$ lyspkj200906010

Publisher's Note Springer Nature remains neutral with regard to jurisdictional claims in published maps and institutional affiliations. 